\title{
Managing Planned Change: The Transition From A Nationalized Organization To A Fragmented Network
}

Val Candy, WestCare Florida/GCC, USA

\begin{abstract}
Organizational change literature has traditionally concentrated on how organizations realign internal resources in an effort to predict and match the needs of the external environment. This paper examines how managing the change process can influence organizational performance measures such as voluntary turnover. The underlying causes of resistance to change and personorganization fit are discussed as the National Health Service (NHS) in the United Kingdom continues to experience upheaval as it shifts from a nationalized institution to a fragmented network of trusts charged with visibly increasing efficiencies.

This paper argues that middle managers may be better placed to communicate the vision of the future to nursing professionals as they simultaneously receive leadership communications and engage in sensemaking activities to interpret, manage, and respond to events. Ultimately, they play the critical role in mitigating a loss of experienced professionals and knowledge capital.
\end{abstract}

Keywords: Healthcare; Change; Communication; Turnover

\section{INTRODUCTION}

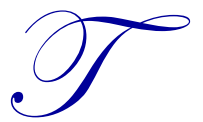

he National Health Service (NHS) of the United Kingdom was established after World War II as part of the means to rebuild infrastructure. Economic resources were reallocated from war efforts to create employment by developing a national, accessible health service, and other social support systems, to provide care and assistance equally to all citizens (Ibrahim et al., 2010). Today, it is considered a worldwide icon representing socialized healthcare, equity, and universality (Baggot, 2004; Ibrahim et al., 2010). By 2005 , with an increasing population of aging citizens, it served a population of over 60 million, had an annual budget of around $£ 40$ billion (approximately $\$ 80$ billion U.S.), and employed over 1.2 million people in various capacities (Ibrahim, et al., 2010).

The current economic climate throughout Europe has called for widely reported austerity measures in many public services. The structure of the NHS healthcare planning has been the subject of intense political debate. The Department of Health (DoH), through its NHS Executive and Direct Trusts, is responsible for maintaining standards, policies, and resources and is under intense public scrutiny to increase efficiencies while simultaneously serving a larger and aging population. In 2010-2011, the NHS Direct Trust reported that it would meet the 2014 deadline to become a network of National Health Foundation Trusts that would enjoy devolved responsibility for budgets and staffing and that many positions would be occupied by part-time employees to afford greater flexibility in service delivery and planning (NHS Direct, 2012, p. 19).

Market-based forces and internal management reforms are driving a more business-like agenda using a network of quasi-governmental Strategic Health Trusts and Authorities. These represent a dramatic change in organizational culture, and the impact of internal reforms, such as increasing productivity through shortened postsurgical hospital length of stays, remains inconclusive (Bevan \& Van De Ven, 2010). The changes are widely publicized as being a threat to the national institution and the perceived quality of healthcare provision, in general. 
The NHS is also suffering from an increase in employee burnout and turnover intentions exacerbated by a critical shortage of nurses (Kahya \& Oral, 2007).

Organizational change literature has traditionally concentrated on how organizations realign internal resources in an effort to match the needs of the external environment. This paper will focus on the literature discussing the nature of the content of change, the processes involved in change, and leading and communicating change using middle managers, rather than leaders, to interpret and deliver critical messages to employees and patients (Armenakis \& Bedein, 1999; Burke \& Litwin, 1992; Beer et al., 1990; Lawrence, 1990; Schein, 1978). A frequent conclusion is that the manner in which change is managed by leadership, and experienced by its recipients, will influence employees' levels of organizational commitment and how they respond to events in the new work environment (Cobb et al., 1995; Kotter, 1996; Spector, 2002).

Human and social capital is widely accepted as a source of long-term competitive advantage (Becker et al., 2001; Holtom et al., 2005; Pfeffer, 1995). This paper will also discuss the role of person-environment fit as a concept considered to be an outcome of change, and that may contribute to the understanding of how to attract and retain talent to enhance organizational performance (O'Reilly, Chatman, \& Caldwell, 1991). Understanding how better to manage the change process will help reduce voluntary turnover as the National Health Service continues to undergo radical transformation and restructuring.

\section{THE NATIONAL HEALTH SERVICE FOUNDATION TRUSTS (NHSFT)}

The United Kingdom's National Health Service Foundation Trusts (NHSFTs) represent a profound change to the structure of the National Health Service (NHS) and the way in which financial and human resources are managed to meet the needs of local communities. Although run locally through a network of Strategic Health Authorities (SHAs), they continue to provide care based on need and not on ability to pay.

In January 2011, the Government provided guidance to SHAs on how to manage the transition from a national trust to a network of local trusts with devolved decision-making authority. The changes have been met by widespread public protests as nurses condemn the coalition government for "breaking its promise to protect the NHS $-50,000$ are set to lose their jobs and vital services are being cut" (Quinn, 2011, p. 6).

\section{Differences In Public And Private Sector Values}

Traditionally, health care or public sector employees have experienced different terms of employment contract than private sector employees. Employees in the public sector are widely considered as motivated by values and attitudes that stretch beyond self-interest or organizational interest. Conversely, employees in the private sector are generally considered as motivated by career development opportunities and the promise of transactional or financial rewards (De Vos, Buelens, \& Schalk, 2003). Within the new network, healthcare organizations have been forced to accommodate a culture in which management and professional perceptions, expectations, and ideologies frequently clash (Schein, 1990). For example, the goal of maximizing bed occupancy to improve efficiencies calls for managerial decisions that may be incongruent with the relevant professional values of the tending nursing staff. Further, whereas money for training nursing staff used to come from government, it is now passed down to the regions and local health care providers, via the SHAs, to decide how the money is spent. This move represents a shift from a socialized care system to a privatized care system.

\section{Person-environment fit $(P-E)$}

Healthcare trust organizations have been forced to adopt a more business-like agenda in an effort to save up to $£ 20$ billion (approx. $\$ 40$ billion). The managed-care climate is placing demands on nurses to make improved efficiencies. Many claim they are leaving the profession because the ambitious plans for restructuring are forcing them to manage budgets rather than care for patients. Hence, addressing the incompatibility, between nurses and the agenda for change, is becoming a priority for the purposes of retention as well as for the recruitment of a highly qualified future workforce. 
According to O'Reilly, Chatman and Caldwell (1991), person-environment (P-E) fit may be defined as "the match, or compatibility, between employees and various aspects of their workplace" (p. 487). Research suggests that an assessment of P-E incompatibility, as a result of organizational change, is associated with intentions to quit (Saks \& Ashforth, 1997). Therefore, expanding on the already implemented broad reforms to the pay and working practices of nurses, the NHSFTs are challenged to develop, and to fund, a plan to retain nurses and secure quality care.

According to Caldwell, Herold, and Fedor (2004), earlier research on P-E fit fails to consider the dynamic nature of change. Its effect on the re-evaluation of an individual's perceived suitability for a particular job setting, or an organizational culture, has been largely ignored. Thus, there is a gap in the literature at a time when radical change, in the shape of organizational restructuring, downsizing, mergers and acquisitions, and globalization are becoming increasingly common.

\section{Compatibility Of Rewards}

Whilst organizational leadership aspires to enhance employee commitment and loyalty, by using clearlystated performance criteria and targets, the extreme emphasis on the tangible elements of the exchange relationship are largely transactional in nature. In contrast, the nursing professional job favors a predominantly relational contract. Therefore, a review of the implementation of change as it impacts those in the immediate work setting, rather than at the top of the organizational hierarchy, may be more likely to find a solution, or intervention, to prevent the loss of qualified nurses.

\section{PERSON-ORGANIZATION (P-O) FIT}

According to O'Reilly, Chatman, and Caldwell (1991), extensive changes to an employee's immediate work setting present the greatest threat to organizational change. This is because they force an employee to make a realignment of personal values against situational factors associated with the job task and work setting. Furthermore, employees frequently view changes as unwelcome. O'Reilly et al. (1991) claim that individual employees also assess their values and expectations against reward systems and organizational cultural norms, symbols, and rituals.

Although the concept of "fit" remains somewhat allusive, it suggests that both task competence and personal values need to be aligned with the prevailing organizational culture ( $\mathrm{P}-\mathrm{O}$ fit). There is evidence that incongruence is related to turnover. O'Reilly et al. (1991) acknowledge the limitations of earlier studies on P-O fit and emphasize how there has been little agreement on whether to define the concept based on normative measures of personality or on job, task, or occupational classifications. However, research continues to explore the suggestion that person-culture (P-C) fit is positively correlated with organizational commitment, satisfaction, and long-term employment with an organization. Indeed, O'Reilly et al. (1991) found evidence that the most reliable response was associated with a measure of intent to leave. In other words, there was a significant positive relationship between P$\mathrm{C}$ incompatibility and intent to leave. Furthermore, intent to leave proved a significant predictor of turnover two years after the survey was administered. The survey used a Likert scale to measure subjective and retrospective reporting. Hence, the results may have been subjected to systematic error in both biased reporting and, arguably, the inappropriate use of a means-based statistical test. However, the results warrant further research in this area.

\section{Turnover}

Although researchers and managers share the goal of reducing turnover and its associated costs, traditionally, turnover theory and research have focused on job dissatisfaction-induced turnover with the intention to leave as its immediate antecedent. However, more recent evidence supports an alternative theory that the immediate cause of most voluntary turnover is an unexpected event (such as a fight with the boss, change in marital status, merger, transfer, or an unexpected job offer) called a "shock" (Holtom, Mitchell, Lee, \& Inderrieden, 2005, p. 337).

Based on data gathered from more than 1,200 employees who had quit an organization, including nurses from eight hospital trusts, Holtom et al. (2005) purport that "shocks" are compared to an individual's values, goals, 
and plans for goal attainment, and, if incompatible, thoughts of leaving occur. They may be positive or negative, may include image violations when an individual's values and goals do not fit in with those of the organization, or may occur when an employee no longer feels the job provides the expected intellectual, emotional, or financial reward.

These authors highlight the expense associated with dysfunctional turnover and noted that quitting is the number one option for nurses as a consequence of a shock. Calculations suggest that an organization would make a revenue-neutral decision by offering a departing nurse 86 percent of salary as an inducement to stay. Whilst the research does not claim to replace job satisfaction or personality as a predictor of intention to leave, it makes a compelling argument for redefining why early identification of the intention to leave is needed to offset the tangible and intangible costs of unexpected turnover. Furthermore, if personality is related to quitting, then strategic human resources management needs to develop recruitment and selection processes to avoid hiring individuals who are likely to leave the organization prematurely.

\section{Resistance To Change}

Unlike earlier research, Oreg (2006) examined both contextual and personality variables' combined role in resisting change and concluded that both categories influenced employees' attitudes. These attitudes, in turn, influenced job satisfaction, organizational commitment, and intention to leave an organization. Dent and Goldberg (1999) argued that resistance to organizational change is the result of fear of a negative consequence (such as losing a job) rather than the change per se. Hence, resistance may be erroneously blamed for failed organizational change. The implication is that management would benefit by implementing change processes with a better understanding of how they affect individuals' subjective experiences in the work setting. It is unclear whether the combined variables acted in a mutually dependent or exclusive manner or whether they interacted to produce the observed experimental results.

\section{Affective, Behavioral, And Cognitive Components}

Oreg (2006) defines resistance as "a tridimensional (negative) attitude toward change, which includes affective, behavioral, and cognitive components" (p. 76). Further, he also distinguishes between resistance to change outcomes and resistance to change processes and claims that the management of these is what causes further resistance, or acceptance, of organizational change. According to Oreg's (2006) model, change outcomes include an employee's power and prestige, job security, and intrinsic rewards. Change processes are trust in management, social influence, and information about the change. Ultimately, the research supports the case that processes, not outcomes, affect the behavioral component of employees' resistance.

Although the tridimensional concept is useful in predicting when an employee might resist change in the immediate work setting, variables influence resistance in a different manner. For example, dispositional resistance has a positive relationship with employees' behavior. Although some antecedents are more strongly related to the outcomes of change, others exert greater influence during the implementation phase of change, or more specifically, on how well, or otherwise, information about the change is communicated. Although the study used a sample of employees working in the defense industry, the structure of the organization, at the pre- and post-change states, reflects that of the NHS and NHSFTs.

\section{Intrinsic Rewards}

According to Oreg (2006), the expectation that a change will be detrimental to the structure and norms of the immediate work setting and daily tasks will enhance resistance to change. For example, where an individual fears a loss of autonomy or less challenging job tasks, as an outcome to the change, intrinsic satisfaction might dissipate. Based on the difference between extrinsic and intrinsic rewards, Oreg (2006) argues that, in spite of employees' reactions to the change process, reactions to the change outcomes will be experienced internally through cognitive and affective evaluations only. No doubt, such findings imply that outcomes have the potential to affect the well-being and, therefore, the productivity of workers. However, the management of radical change may need to first address how the processes are communicated to employees since they are the determinants of overt and conscious decisions and behavior, including turnover and planned quitting. 


\section{MIDDLE MANAGEMENT: SENSEMAKING}

Balogun and Johnson (2004) examined the role of middle managers in a recently privatized utility in the United Kingdom and found that they fulfilled a dual role as both change agents and change recipients in a radical planned program of change. They argued that the role of the middle manager is frequently relegated to second place during the implementation phase of change. More attention is given to organizational leadership, although the middle manager is better situated to communicate the change process to others, including customers. In addition, the middle manager is required to initiate structure and to interpret outcomes in the absence of senior decision makers. This means that the middle manager enjoys a degree of referent and expert power that can be used to either positively influence organizational change, or to disrupt it.

\section{Making sense of restructuring}

For the purposes of this project, Balogun and Johnson's (2004) findings are considered generalizable to nursing professionals. Nurses are considered to be the middle managers of the NHSFTs as they try to make sense of the transition from a national, hierarchical structure to a modular form characterized by decentralized decisionmaking. According to Balogun and Johnson's (2004) argument, nurses fit the personal and job characteristics to be described as "sensemakers". However, although "they connect an organization's strategic and operational levels through mediation, negotiation, and interpretation", they are underappreciated by senior management during planned radical change (Huy, 2001, p. 72).

In a study of "sensemaking" during the implementation of forced organizational change, Balogun and Johnson (2004) found that "lateral processes of "sensemaking" were critical to the organization" (p. 523). It is a conversational and narrative process and, therefore, is a change process associated with communicating information. Making sense of, and communicating change, may be achieved by verbal or written methods, with formality or informality, through the use of storytelling and through symbolic actions and behaviors.

According to Weick et al. (2005), sensemaking is a retrospective, presumptive, social and systemic process that individuals use to create an internal sense of stability where an external state of flux is perceived. Further, they argue that organizations emerge, or are enacted, through sensemaking rather than the other way round. In a study of knowledge management and intellectual capacity, Spender and Tsoukas (2006) argue that sensemaking and organizing attempt to make sense of equivocal inputs and then enact this sense by taking action based upon associated perceptions. According to Hatch (2006), Weick's theory of enactment highlights how rationality is influenced by perception and retrospection when agreeing upon responses within a given environment. Further, any analysis of the relationship can take place only after clearly defined organizational boundaries have been agreed. In turn, the defining characteristics are subjectively selected based on the underlying reasons for analyzing the organization's relationship with its environment.

Nurses may engage in "sensemaking" with other nurses to clarify any ambiguity and uncertainty resulting from plans for restructuring. Communicating with senior management, while important, was found to interfere with the "sensemaking" process. The persistence of blame, admonished by senior managers when confusion emerged in daily operations, caused some middle managers to complain about inappropriate control mechanisms in the postchange culture. This was especially harmful to individuals as they had been primed to expect a greater sense of empowerment.

Unexpectedly, tensions emerged within middle management, but not between senior and middle management, as they sought to impose a new and more directive management style. Frustration with the change process, including the introduction of more formal contracts, called for planned interventions. Such interventions ranged from new structures, systems, roles, as well as the provision of counseling services to help individuals to adjust to the change or to exit the organization.

Balogun and Johnson (2004) concluded that different change processes produce different behaviors in change recipients. In the case of top-down directive change, involving significant restructuring and work practices, leadership may need to delegate the process of communicating information to middle managers. This might help to 
avoid further ambiguity or negative attitudes during the implementation phase. However, bottom-up change processes may be more productive when work units attempt to collaborate or merge services in an effort to increase efficiencies.

\section{Leadership Effectiveness}

Gilley, Dixon, and Gilley (2008) conducted a two-year longitudinal study to examine the characteristics of leadership effectiveness with respect to change and innovation. They found the main reasons for unsuccessful change initiatives to be a lack of organizational leadership's recognition, or rewards, for those who change, an inability to motivate others to change, and failure to understand change implementation techniques that are barriers to successful change.

Gilley et al. (2008) concluded that employees at all organizational levels have little confidence in leadership's ability to manage change and quoted how "leadership is often cited as a significant barrier to change, despite their self-reports to the contrary" (p. 164). The findings also suggest that communication is particularly important to instilling a sense of confidence during the implementation phase of change. However, the research does not throw light on whether a leader, who oversees changes in the delivery of frontline services, has the authority to reward or to communicate on the risks of not changing without first deferring to more senior management. Two critical questions remain unasked. Firstly, to what extent can middle managers create a sense of urgency for change; and secondly, whether they have the authority to reward employees who demonstrate the required behaviors for the change to become institutionalized? Although not discussed here, these questions raise issues surrounding employers' and employees' use of control. For some, control is used as a coping mechanism and may influence withdrawal and turnover in much the same way as do shocks and attitudes (Holtom, Mitchell, Lee, \& Inderrieden, 2005).

\section{Communication}

Whelan-Berry and Somerville (2010) examined the need for leaders to consider how to link change drivers to practices during the implementation of organizational change. They defined change drivers as "the events, activities, or behaviors that facilitate the implementation of change" (p. 179) and linked each one to an organizational change process, or step, commonly accepted within earlier change process literature.

In a review of the literature emphasizing the implementation phase of change, Whelan-Berry and Somerville (2010) argued that sustaining the change may take as long as seven years when it involves a significant organizational cultural shift. They argued that since resistance to change is an internal process which occurs at the individual level, understanding how to overcome it will help leaders develop strategies and tactics for sustaining the momentum of change throughout the organization.

Whereas, Whelan-Berry and Somerville (2010) argued that change drivers are not linked to the creation of a compelling vision, understanding how to filter the impact of change down through specific departments, teams, or job holders is critical to managing the transition. Hence, the authors proposed that enactment of the vision happens at the individual level as employees change their values, attitudes, and behaviors to accommodate the change. The authors also claimed that "while top leadership support is critical, leadership support from leaders throughout the organization, including teams, departments, and locations, is critical to successful change implementation" (p. 180). Ultimately, for the management of change to be successful and sustainable, the communication of the organizational change process should encourage employee participation during the planning phase. In addition, matching the reward and appraisal system to business goals will help institutionalize the change.

\section{Job Evaluation}

Job evaluations provide an unbiased and formal framework for determining and comparing the relative worth of tasks and outcomes associated with a job. They may be designed taking into consideration both internal and external equity. Kahya and Oral (2007) conducted an extensive study of nursing jobs and evaluations within the NHS and claimed that only 14 of the 19 nursing jobs held at local hospitals could readily be mapped onto the 
national pay structure. Furthermore, they found large variations in the types of work and responsibilities performed by nurses in different departments and health trusts.

The Department of Health commissioned the survey to gather data for a new national job evaluation for nurses within the National Health Service (NHS JE), against which quantifiable pay scales could be attached. This is arguably the most controversial change in human resource management within the NHS since its inception. It formed the foundation for a change in career structure as well as terms and conditions of employment. Although healthcare unions (UNISON) and the Royal College of Nursing (RCN) claim it goes some way to addressing the need to improve morale and reduce turnover, its focus on achieving this through a more equitable pay structure remains a more transactional than relational tactic.

Whilst there is some concern about how the survey disregards the role of how to communicate within the NHS JE itself, perhaps an even more critical oversight is that its findings and recommendations have been applied to a pre-change climate. This leaves leadership still challenged to initiate structure in a highly turbulent environment. In addition, leadership must not overlook the importance of developing a fair and complementary compensation package that matches the new climate and the little understood "semi-privatized" culture. In support of Balogun and Johnson's (2004) findings, a communication strategy based on bottom-up processes may help nursing professionals to balance (or to merge) the perceived competing priorities of their former roles (or values) with newly imposed organizational outcomes.

Whilst Kayla and Oran (2007) concede the limitations of the new job evaluation and pay system in failing to more adequately define and differentiate nursing jobs, they overlook the need to address other morale-boosting processes based on values traditionally associated with the care worker. For example, there is no recommendation for how the NHSFTs should plan and fund local programs to support the continuing professional development of nursing staff. This may be of particular concern for those seeking a long-term career within the new organizational structure. Neither does the study adequately support the need for training on how to use the appraisal system appropriately at a local level. This is a potential source of conflict for when the new NHSFTs assume total responsibility for all staffing and developmental needs of new recruits and existing nurses.

\section{RADICAL CHANGE IN THE NATIONAL HEALTH SERVICE}

Great Britain's coalition government recently announced that it would continue to implement basic reforms to the NHS. No doubt, wishing to reduce the risk of losing a second term in office, it has agreed to slow down the more controversial plans to introduce the privatization of certain medical services to this long-cherished institution that was founded in 1948 on socialist values and employing more than 1.3 million people. The NHS chief executive described the plans as "so significant they can be seen from space" (Quinn, 2011). However, the NHSFTs remain challenged to develop a communication strategy and to implement radical changes to the structure and culture of the immediate work setting for nurses. Both of these issues need to be addressed simultaneously and linked to strategic business goals. This might ensure that the issue of retention of experienced nursing professionals is framed as a critical measure of performance rather than a lamentable, but inevitable, casualty of change.

\section{Leading Cultural Change}

Leadership is keen to portray nurses as the enduring symbol of care and compassion of the health care industry. Traditionally, the public and politicians have hailed them as the nation's "angels" who tend to the needs of a growing number of patients within a socialized culture. Such patients are accustomed to receiving both outpatient and inpatient care without the worry of cost. Even a slight shift in the focus of nurses' work, from providing effective care (based on the physical, psychological, and sociological needs of an individual patient) to managing and supervising resources for greater efficiencies, has led to concerns about overwork. Error rates, caused by downshifting and understaffing, are widely believed to have contributed to the shortage of nurses and nursing professionals. These issues may be captured within the literature under the umbrella term of "professionalbureaucratic tensions". Such tensions arise as nurses are forced to sacrifice elements of the tailored care model, advocated by their profession, in favor of a bureaucratically-driven cost control model, stipulated by the employing organization (Maben, Latter, \& Clark, 2006). 


\section{Participative Style Of management}

To effectively implement change and enhance the retention rate of existing nurses, the recommendation made by this paper supports a participative and consultative style of management in the immediate workplace. Whilst this contradicts earlier research that favors a more directive style (Balogun \& Johnson, 2004), given the enormous scope of change and the absence of a true and imminent deadline for achieving the change, it is suggested that leadership within the NHSFTs take time to develop a communication strategy. Such a strategy should include a process for seeking input from the very nurses expected to execute the change and who work at the interface with the nation's growing patient population. Arguably, they form the layer of middle management, striving to make sense of the change and struggling to interpret and promote new guidelines within the new institutions. They are charged with performing these new tasks, although they had no formal power to influence the development of the new policies and procedures. Some may argue that the process of consulting with the RCN and UNISON on such a large-scale change should suffice as a communication strategy. However, this paper contends that whenever a consultation exercise is warranted, it would call for local communication strategies and policies to ensure the information is accurately and widely made available for those working on the front line with patients.

\section{Empowerment}

Communicating quality information about organizational changes in NHSFTs would expect to support earlier research that observed an increase in positive outcomes. Such outcomes included enhanced feelings of empowerment, feelings of control in the immediate work setting, and job satisfaction (Bordia, Hunt, Paulsen, Tourish, \& DiFonzo, 2004). These are indisputably important factors when addressing retention issues. This paper also considers top-down communication necessary to enable leaders (at all levels within the NHSFTs) to create a sense of urgency for change (Kotter, 1996). Top-down communications should continue to articulate a unifying vision for the future toward which all nurses can aspire in their daily job tasks. This might help in inspiring greater reports of affective organizational commitment rather than the less desirable continuance commitment. The latter form of organization commitment is used when nurses evaluate the cost of leaving the organization and is mentioned in anecdotal accounts when there is a general distrust of management systems (Laschinger et al., 2001).

\section{Managing Professional-Bureaucratic Tensions}

Maben, Latter, and Clark (2006) examined the effect of organizational change on professional-bureaucratic tensions among nurses in the United Kingdom. They argued that unless these tensions could be alleviated, the future vision of a new healthcare industry, characterized by decentralized control and greater autonomy, was at risk of disintegrating into little more than a political dream. Building on the work of Allen (2004), they found evidence to support the argument for designing an intervention to help nurses understand why change is needed. Further, they argued that such an intervention might prove more effective in reducing resistance if the core message was delivered by a supervising nurse professional rather than by top management. Such a strategic tactic might help experienced nurses cope with, and reconcile, what they currently perceive to be competing ideological and practitioner cultures within the NHSFTs.

Maben et al. (2006) concluded that nurses' former ideological role of caring effectively for patients, with empathy and compassion, was giving way to more task-oriented and dispassionate practices. This is widely accepted by the public, the RCN, and UNISON as a leading cause for concern in developing retention strategies to offset the excessive costs associated with hiring temporary workers to perform essential tasks. Experienced nursing professionals report that the accumulated stress caused by trying to merge the "care versus efficiency" competing cultures also results in additional workloads that increase levels of absenteeism.

In addition, many nurses are identifying gaps in existing skills that are fundamental to their new roles and which will need to be acquired and developed if the organization is to succeed. The effects, or outcomes, of these combined changes were measured in terms of diminished morale, job satisfaction, and retention. The results (Maben et al., 2006) suggest that nurse education reforms, which were designed to address these different value systems, were not only exacerbating the situation, but also contributing to contemporary higher levels of turnover and burnout than those experienced in several decades. 


\section{Communication And Motivation}

Allen (2004) argues that nurses lack control and experience reduced levels of self-confidence. These factors have contributed to the gravest shortage and retention issues faced by the NHS since the early 1970s. Allen (2004) claims that leaders, at all levels of an organization, need to support nurses to help them modify their ideals within a framework of what is realistically possible within the new NHSFTs. Similarly, Gilley et al. (2008) argue that effective implementation of change and innovation is dependent upon communicating with and motivating employees. This is also the case with unwelcome or negative information and events, which can be accommodated if they are properly communicated to those whom the changes impact.

Gilley et al. (2008) argue that predictors of individual motivation are job satisfaction, perceived equity, and organizational commitment. These researchers also claim that the predictors are primarily realized through the work environment. The implication of this position is that leaders need to create an organizational culture and climate where barriers to individual motivation and performance are understood and overcome. One such barrier within NHSFTs is the reported lack of trust in leadership as organizational relationships are now based on decentralized control, and structures have flattened to make cost efficiencies. The resultant intensified workload and shortage of qualified nurses has become a focal issue which leadership cannot afford to ignore. It must earn the trust of nurses who are instrumental in helping the new health trusts reach their vision of quality care.

\section{Trust In Leadership}

According to Laschinger, Finnegan, and Shamian (2001), as organizations restructure or downsize for improved efficiencies, trust in management is critical to determining organizational culture, individual performance, and organizational commitment. They claim that trust is becoming all the more important as it forms the basis of the mutual understanding of shared values between employees and leaders. These shared values, in turn, form the foundation for organizational commitment and loyalty. Unless an organization operates within a culture of strict mechanistic control, people who mistrust each other will not work together (Laschinger et al., 2001). Conversely, organizations that provide access to information, resources, support, and opportunities for personal and professional development empower employees.

Given how the NHS has relinquished its mechanistic control and authority for centralized decision-making on all matters of human and financial resources, local NHSFT leaders must ensure they create a culture of trust in order to win the hearts and minds of nursing professionals. This means that leaders need to provide quality information and the necessary resources, including opportunities for professional development, to enable nurses to experience high levels of job satisfaction, organizational commitment, and ultimately, high performance outputs.

\section{CONCLUSION}

According to Kotter (1996), leaders can never over communicate quality information about organizational change. Using new symbols and language that encapsulate the change not only builds support for the change, but also embodies the change in the individual members of the organization. Effective change may be considered a byproduct of a leader's openness and skill in involving employees in the process of change. However, communication is a two-way process that is more likely to be achieved when leadership listens, as well as talks, to those who are expected to implement the impending change.

The Strategic Health Authorities and the National Health Service Foundation Trusts in the United Kingdom would benefit by seeking input from nursing professionals who are well placed to provide feedback from the patients and communities they serve. Further, the very act of consulting with nurses might help generate feelings of autonomy, empowerment, and enhanced levels of job satisfaction and organizational commitment (Gilley et al., 2008). To complement top leadership's central message concerning restructuring, this paper recommends interventions be designed to communicate with nurses in their immediate work setting (Balogun \& Johnson, 2004). This could take the form of coaching or mentoring to help nurses recognize how their personal values, assumed to reflect a professional care culture, can be compatible with the new managed care climate. 
This approach could also help toward the retention of experienced nurses who report intentions to leave their organization (Holtom et al., 2005). It would give them an opportunity to vent about misgivings, to identify developmental needs, and to agree on actions to fill any gaps in knowledge, skill, or ability their expended role may create. Few would argue that quality care is contingent upon the retention of satisfied nursing professionals, who are committed to both their professional ideals, and their employing health care organization. Surely, achieving this is the ultimate goal of the controversial structural and cultural changes. However, unless leadership communicates effectively and designs reward systems for nurses that complement the new formal structure, it risks continued attempts to sabotage the process.

\section{AUTHOR INFORMATION}

Val Candy is a doctoral learner of management with Capella University focusing in marketing and organizational performance. She earned her BS and MS with Hodges University. She has worked extensively in leadership positions and upper management both in the United Kingdom and in the United States within the public and private sector. She is published in the areas of leadership, strategic planning, and business economics research. She can be contacted at vucandyms@gmail.com

\section{REFERENCES}

1. Allen, D. (2004). Re-reading nursing and re-writing practice: Towards an empirically based reformulation of the nursing mandate. Nursing Inquiry, 11(4), 271-283.

2. Armenakis, A. A., \& Bedeian, A. G. (1999). Organizational change: A review of theory and research in the 1990s. Journal of Management, 25(1), 293-315.

3. Baggot, R. (2004). Health and healthcare in Britain ( $3^{\text {rd }}$ ed.). London, UK: Macmillan Press Ltd.

4. Balogun, J., \& Johnson, J. (2004). Organizational restructuring and middle manager sensemaking. Academy of Management Journal, 47(4), 523-549.

5. Becker, B. E. Huselid, M., \& Ulrich, D. (2001). Linking people, strategy and performance. Boston: Harvard Business School Press.

6. Beer, M., Eisenstat, R. A., \& Spector, B. (1990, November- December). Why change programs don’t produce change. Harvard Business Review, 158-166.

7. Bevan, G., \& Van De Ven, W. P. (2010). Choice of providers and mutual healthcare purchasers: Can the English National Health Service learn from the Dutch reforms? Health Economics Policy and Law, 5(1), 343-363.

8. Bordia, P., Hunt, E., Paulsen, N., Tourish, D., \& DiFonzo, N. (2004). Uncertainty during organizational change: Is it all about control? European Journal of Work \& Organizational Psychology, 13(3), 345-361.

9. Burke, W., \& Litwin, G. (1992). A causal model of organizational performance and change. Journal of Management, 18(1), 523-545.

10. Caldwell, S. D., Herold, D. M., \& Fedor, D. (2004). Toward an understanding of the relationships among organizational change, individual differences, and changes in person-environment fit: A cross-level study. Journal of Applied Psychology, 89(5), 868-882.

11. Cobb, A. T., Wooten, C., \& Folger, R. (1995). Justice in the making: toward understanding the theory and practice of justice in organizational change and development. Research in Organizational Change and Development, 8(1), 243-295.

12. Dent, E. B., \& Goldberg, S. E. (1999). Challenging resistance to change. Journal of Applied Behavioral Science, 35(1), 25-41.

13. De Vos, A., Buyens, D., \& Schalk, R. (2003). Psychological contract development during organizational socialization: Adaptation to reality and the role of reciprocity. Journal of Organizational Behavior, 24, 537-559.

14. Gilley, A., Dixon, P., \& Gilley, J. W. (2008). Characteristics of leadership effectiveness: Implementing change and driving innovation in organizations. Human Resource Development Quarterly, 19(2), 153-169.

15. Hatch, M. J. (with Cunliffe, A. L.). (2006). Organization theory: Modern, symbolic, and postmodern perspectives (2nd ed.). New York: Oxford University Press.

16. Holtom, C., Mitchell, T., Lee, T, \& Inderrieden, E. (2005). Shocks as causes of turnover: What they are and how organizations can manage them. Human Resource Management, 44(3), 337-352. 
17. Huy, Q. N. (2001). In praise of middle managers. Harvard Business Review, 79(5), 72-79.

18. Ibrahim, A. D., Price, A., Khalfan, M, \& Dainty, A. (2010). Construction procurement strategies of National Health Service in the U.K: A critical review. Journal of Public Procurement, 10(1), 31-67.

19. Kahya, E., \& Oral, N. (2007). Job evaluation for clinical nursing jobs by implementing the NHS JE system. Journal of Nursing Management, 15,740-748.

20. Kotter, J. (1996). Leading change. Boston, MA: Harvard Business School Press.

21. Laschinger, H., Finnegan, J., \& Shamian, J. (2001). The impact of workplace empowerment, organizational trust on staff nurses' work satisfaction and organizational commitment. Health Care Management Review, 26(3), 7-23.

22. Lawrence, P. (1990). Why organizations change. In A. M. Mohrman et al. (Eds.). Large-scale organizational change, pp. 48-61. San Francisco: Jossey-Bass.

23. Maben, J., Latter, S., \& Clark, J. (2006). The theory-practice gap: Impact of professional-bureaucratic work conflict on newly qualified nurses. Journal of Advanced Nursing, 55(4), 465-477.

24. National Health Service Direct (2012). Annual Report and Accounts 2010/2011. Retrieved from http://www.nhsdirect.nhs.uk/about/corporateinformation/ /media/downloads/nhsdannualreportaccounts 201 0-11.ashx March 16, 2013.

25. Oreg, S. (2006). Personality, context, and resistance to organizational change. European Journal of Work and Organizational Psychology, 15(1), 73-101.

26. O'Reilly, C. A., III, Chatman, J. A., \& Caldwell, D. (1991). People and organizational culture: A profile comparison approach to assessing person-organization fit. Academy of Management Review, 25, 487-516.

27. Pfeffer, J. (1995). Producing sustainable competitive advantage through effective management of people. Academy of Management Executive, 9(1), 55-72.

28. Quinn, B. (2011, May, 28). Anti-cuts groups descend upon bank in NHS protest. The Guardian, p. 3.

29. Saks, A. M., \& Ashworth, B. E. (1997). A longitudinal investigation of the relationships between job information sources, applicant perceptions of fit, and work outcomes. Personnel Psychology, 40, 437-453.

30. Schein, E. H. (1990). Organizational culture. American Psychologist, 45, 109-119.

31. Spector, P. E. (2002). Employee control and occupational stress. American Psychological Society, 11(1), 153-156.

32. Spender, J. C., \& Tsoukas, H. (2006). Method, philosophy and empirics in KM and IC/Commentary: On Spender's "method, philosophy and empirics in KM and IC". Journal of Intellectual Capital, 7(1), 12-28. Retrieved from ABI/INFORM Global.

33. Weick, K. E., Sutcliffe, K. M., \& Obstfeld, D. (2005). Organizing and the process of sensemaking. Organization Science, 16(4), 409-421. Retrieved from ABI/INFORM Global.

34. Whelan-Berry, K. S., \& Somerville, K. A. (2010). Linking change drivers and the organizational change process: A review and synthesis. Journal of Change Management, 10(2), 175-193. 
NOTES 